\title{
Detection of influenza B viruses with reduced sensitivity to neuraminidase inhibitor in Morocco during 2014/15 season
}

F. Elfalki' ${ }^{2}$, H. Ihazmad' ', A. Bimouhen', Z. Regragui', S. Benkaroum ', Y. Bakri² and A. Barakat ${ }^{1}$

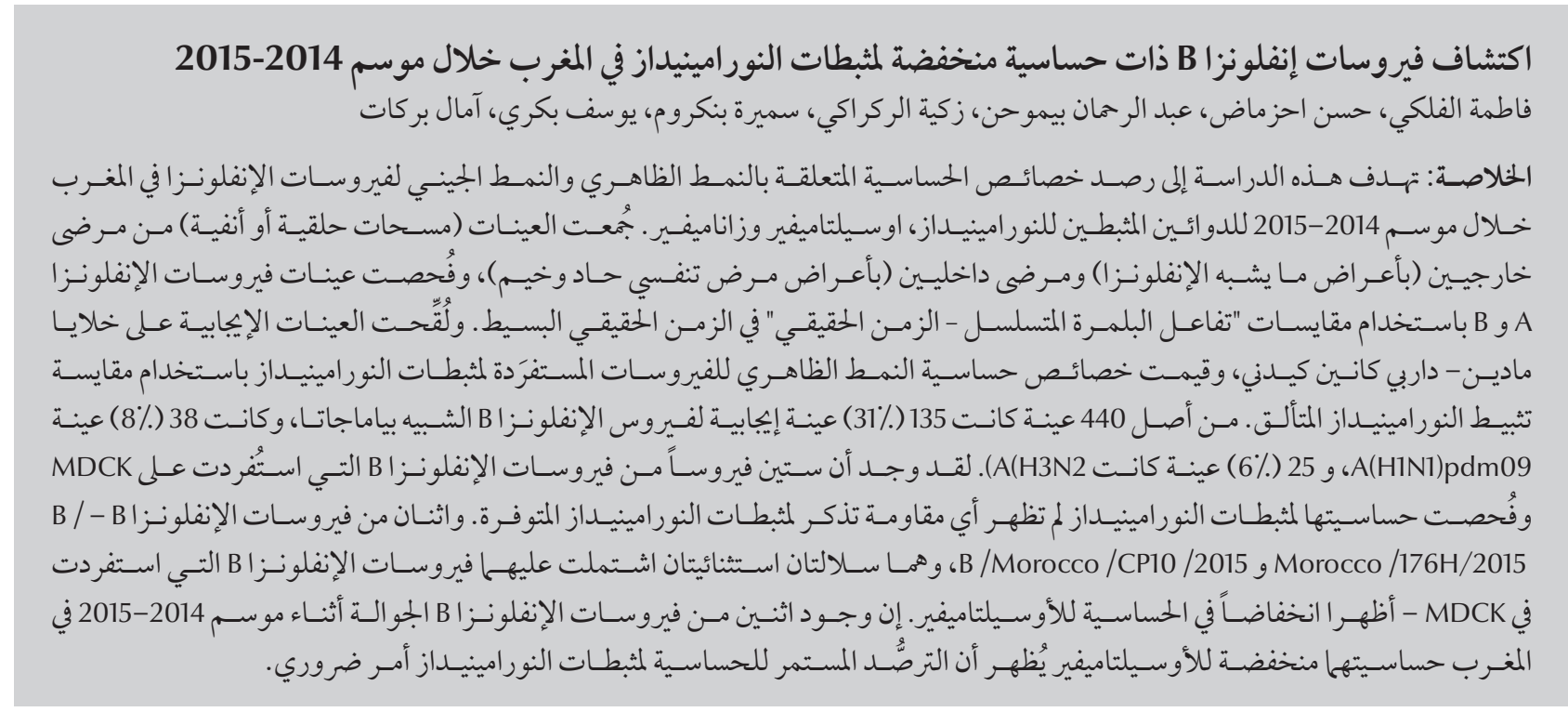

ABSTRACT We monitored phenotypic and genotypic susceptibility of influenza viruses circulating in Morocco during 2014-2015 to oseltamivir and zanamivir. Throat and nasal swab specimens were collected from outpatients (with influenza-like illness) and inpatients (with severe acute respiratory illness) and tested for influenza viruses using real-time reverse transcription polymerase chain reaction. Positive samples were inoculated in MDCK cells and virus phenotypic susceptibility to neuraminidase inhibitors (NAIs) was assessed using fluorescent NA inhibition. Of 440 specimens, 135 were positive for influenza B Yamagata-like virus, 38 were $A(H 1 N 1) p d m 09$ and 25 were A(H3N2). Sixty influenza B viruses isolated from MDCK cells showed no significant resistance to NAls. However, two of these strains, B/Morocco/176H/2015 and B/Morocco/CP10/2015, showed reduced susceptibility to oseltamivir. The two influenza $B$ viruses with reduced susceptibility to oseltamivir show that ongoing NAI susceptibility surveillance is essential.

\section{Maroc : dépistage de virus de la grippe B présentant une sensibilité réduite à l'inhibiteur de la neuraminidase durant la saison 2014-2015}

RÉSUMÉ Nous avons surveillé le profil de sensibilité phénotypique et génotypique des virus de la grippe à l'oseltamivir et au zanamivir durant la saison 2014-2015 au Maroc. Des échantillons ont été prélevés (par frottis de gorge ou écouvillonnage du nez) chez des patients externes (présentant un syndrome de type grippal) et chez des patients hospitalisés (présentant une infection respiratoire aiguë sévère). Ils ont été soumis au test de détection des virus de la grippe A et B via la méthode d'analyse RT-PCR simplex en temps réel. Les échantillons positifs ont été inoculés à des cellules rénales canines Madin-Darby (MDCK) et le profil de sensibilité phénotypique des virus isolés aux INA a été évalué au moyen du test d'inhibition de la neuraminidase (NA) par fluorescence. Sur 440 échantillons, 135 (31\%) étaient positifs au virus de la grippe $B$ de type Yamagata, $38(8 \%)$ à celui de la grippe $A(H 1 N 1) p d m 09$ et $25(6 \%)$ à celui de la grippe $\mathrm{A}(\mathrm{H} 3 \mathrm{~N} 2)$. Soixante virus de la grippe B isolés sur les culture de cellules MDCK et soumis au test de sensibilité aux INA n'ont démontré aucune résistance significative aux INA. Toutefois, deux de ces souches, la B/Maroc/176H/2015 et la B/Maroc/CP10/2015, ont démontré une sensibilité réduite à l'oseltamivir. Les deux virus de la grippe B ayant une sensibilité réduite à l'oseltamivir montrent l'importance d'une surveillance permanente de la sensibilité à l'inhibiteur de la neuraminidase. 


\section{Introduction}

Human influenza is responsible for an estimated $250000-500000$ deaths annually worldwide (1). Although vaccination remains the primary means for the prevention of influenza, antiviral drugs are a key component in the prophylaxis and treatment of the population at high risk of influenza-associated complications. Antiviral drugs might be the only medical intervention available during the early phases of a pandemic. Two classes of specific anti-influenza drugs have been developed to date: the M2 ion channel blockers (adamantanes) and the neuraminidase inhibitors (NAIs) (oseltamivir and zanamivir) (2).

Susceptibility of influenza B viruses to NAIs has been less studied than susceptibility of influenza A viruses. Influenza B viruses, classified into 2 genetic lineages Victoria and Yamagata, are circulating globally with unpredictable temporal and spatial distributions (3). Recently, low-level resistance to NAIs has been documented but the known molecular markers, transmissibility and fitness of NAI-resistant variants are not well established (4). A worldwide antiviral surveillance study of influenza B viruses from 2004 to 2008 identified 1 extreme outlier and 3 mild outliers among 1070 viruses tested (0.4\%) (5). A later study among 346 influenza B viruses isolated worldwide during 2011 identified 2 (0.6\%) with reduced susceptibility to NAIs (6). These resistant viruses can emerge under drug selection pressure or occur naturally without drug interventions (7), and are associated with amino acid substitutions at the conserved NA residues or in surrounding locations (8).

In this study, we evaluated the sensitivity to oseltamivir and zanamivir of influenza B viruses isolated from specimens collected from the National Influenza Surveillance System in Morocco during the 2014-2015 season.

\section{Methods}

\section{Sample collection}

Throat and nasal swab specimens were collected during the 2014-2015 season from outpatients presenting with influenza-like illness (ILI) and inpatients presenting with severe acute respiratory illness (SARI). ILI was defined as ARI with onset during the past 10 days, temperature $\geq 38{ }^{\circ} \mathrm{C}$ and cough (9). SARI was defined as ARI with history of fever or temperature $\geq 38^{\circ} \mathrm{C}$ and cough, with onset of symptoms in the past 10 days and requiring hospitalization (10). After collection, the samples were immediately stored at $4{ }^{\circ} \mathrm{C}$ until delivery to the National Influenza Centre located at the Institut National d'Hygiène in < 48-72 hours (9.10).

\section{Influenza B virus screening}

Viral RNA was extracted directly from the collected specimens by automatic extraction (iPrep Purelink Virus Kit; ( Thermo Fisher Scientific ,Carlsbad, CA 92008 USA). A $25-\mu \mathrm{L}$ reaction volume contained $12.5 \mu \mathrm{L} 2 \times$ polymerase chain reaction (PCR) Master Mix, $5.5 \mu \mathrm{L}$ RNase-free water, $0.5 \mu \mathrm{L} 40 \mu \mathrm{M}$ reverse primer, $0.5 \mu \mathrm{L} 40 \mu \mathrm{M}$ forward primer, $0.5 \mu \mathrm{Ll}$ probe $10 \mu \mathrm{M}$ (influenza A or B ), $0.5 \mu$ Lenzyme mix (SuperScript IIIRT/ Platinum Taq Mix; (Thermo Fisher Scientific, Calsband, CA 92008 USA and $5 \mu \mathrm{L}$ viral RNA extract. Amplification was carried out in a 7500 Fast 96-Well Thermocycler (Applied Biosystems, Foster City, CA, USA) with a single reverse transcription step $\left(50{ }^{\circ} \mathrm{C}\right.$ for 30 minutes), Taq inhibitor activation (95 ${ }^{\circ} \mathrm{C}$ for 2 minutes), PCR amplification over 45 cycles $\left(95^{\circ} \mathrm{C}, 30\right.$ seconds $/ 55$ ${ }^{\circ} \mathrm{C}, 30$ seconds), according to the US Centers for Disease Control (CDC) protocol (11). Influenza B primers and probes were provided by $\mathrm{CDC}$ as part of a material transfer agreement that ensures privacy and non-publication.

\section{Subtyping of influenza B virus lineages}

The $25-\mu \mathrm{L}$ reaction volume contained $12.5 \mu \mathrm{L} 2 \times$ PCR Master Mix, $5.5 \mu \mathrm{L}$ RNase-free water, $0.5 \mu \mathrm{L} 25 \mu \mathrm{M}$ reverse primer, $0.5 \mu \mathrm{L} 25 \mu \mathrm{M}$ forward primer, $0.5 \mu \mathrm{L}$ probe $25 \mu \mathrm{M}$ (Yamagata or Victoria; (Thermo Fisher Scientific ,Calsband, CA 92008 USA), 0.5 $\mu \mathrm{L}$ enzyme mix (SuperScript III RT/ Platinum Taq Mix), and $5 \mu \mathrm{L}$ viral RNA extract. Amplification was carried out in a 7500 Fast Thermocycler (Applied Biosystems) with a single reverse transcription step at $50{ }^{\circ} \mathrm{C}$ for 30 minutes, Taq inhibitor activation at $95^{\circ} \mathrm{C}$ for 15 minutes, and PCR amplification over 45 cycles $\left(95^{\circ} \mathrm{C}, 10\right.$ seconds $/ 54^{\circ} \mathrm{C}, 30$ seconds $/ 72^{\circ} \mathrm{C}, 10$ seconds) (11).

\section{Virus isolation}

PCR-positive samples $(100 \mu \mathrm{L})$ were inoculated into 2 wells of a 24 -well plate with $70-90 \%$ confluent monolayers of MDCK cells. After 30 minutes adsorption at room temperature, $2 \mathrm{~mL} /$ well minimal essential medium supplemented with $2 \mathrm{mg} / \mathrm{mL}$ tosyl phenylalanyl chloromethyl ketone trypsin was added. Cells were incubated in sealed bags at $35^{\circ} \mathrm{C}$. After 2 days, viral multiplication was detected by haemagglutination assay using guinea pig red blood cells. Virus identification was carried out by haemagglutination inhibition test usingWHO Haemagglutination inhibition reagent kits (12).

\section{NAls}

Oseltamivir carboxylate, the active compound of the ethyl ester prodrug oseltamivir phosphate, was kindly provided by Hoffmann-La Roche (Basel, Switzerland), and zanamivir by GlaxoSmithKline (Uxbridge, UK).

\section{Reference viruses}

A matching pair (sensitive and resistant to oseltamivir and/or zanamivir) of reference viruses for each subtype to be tested was included in each assay run. The panel containing drug-sensitive/ 
resistant control virus pairs was delivered by the WHO Collaborating Centre, Melbourne (13).

\section{Fluorescent NA inhibition assay}

The phenotypic evaluation of influenza $B$ virus susceptibility to NAIs was performed using the NA-Fluor Influenza Neuraminidase Assay Kit (Applied Biosystems/Life Technologies, Carlsbad, CA, USA) in 96-well, opaque black, flat-bottom microplates, according to the CDC protocol (available from the CDC upon request: fluantiviral@cdc.gov). This assay utilized 2-(4-methylumbelliferyl)- $\alpha$-D-N-acetyl neuraminic acid (MUNANA) (Applied Biosystems, Foster City, CA, USA) as substrate. Viruses were diluted at concentrations corresponding to the target fluorescence signal generated by $1000 \mathrm{pmol} /$ well of 4-methylumbelliferone standard. Subsequently, $25 \mathrm{~mL}$ of each diluted virus was mixed with $25 \mathrm{~mL}$ of a range of concentrations of each NAI inhibitor (0.0015-4000 nM) and incubated at $37^{\circ} \mathrm{C}$ for 45 minutes. Then, $50 \mathrm{~mL}$ of $200 \mathrm{mM}$ MUNANA was added to the virus and inhibitor mixture and incubated at $37^{\circ} \mathrm{C}$ for 1 hour. The reaction was stopped with 100 mL NA-Fluor Stop Solution. Fluorescence was detected on the Victor X3 (WSLH. Series Multilabel Plate Readers PerkinElmer, Inc. Waltham, MA 02451 USA) equipped with filters for excitation $(\lambda=365 \mathrm{~nm})$ and emission $(\lambda=450 \mathrm{~nm})(14)$.

\section{Data analysis}

Raw fluorescence NA inhibition assay data expressed as RFU were plotted against drug concentration (nM) to calculate the median 50\% inhibitory concentration (IC50) using JASPER version 1.2 curve-fitting software (CDC, Atlanta, GA, USA) (15).

\section{Interpretation of $\mathrm{IC}_{50}$ values}

Fold changes in IC50 were determined by comparing the IC50 of test viruses with the mean IC50 (outliers excluded) according to drug and influenza type/ subtype (16). IC50 was interpreted using the WHO Antiviral Susceptibly Expert Working Group criteria for influenza B viruses: < 5-fold change in IC50 represents normal inhibition; 5-50-fold change represents reduced inhibition; and $>50$-fold change is highly reduced inhibition (17).

\section{Sequencing of the NA gene}

Real-time PCR was carried out for individual gene fragments with the primers panel from the $\mathrm{CDC}$ with PCR conditions as described in the MyTaq One-step RT-PCR Kit (Bioline, London, UK). The PCR products were purified using the GE Healthcare/USB ExoSAP-IT PCR Product Clean-Up (Affymetrix, Cleveland, OH, USA). Purified PCR products were sequenced with the use of the ABI Big Dye Terminator, version 3.1 (Applied Biosystems) and M13 primers (CDC protocol unpublished). The latest $\mathrm{PCR}$ products were purified using Big Dye X Terminator purification (Applied Biosystems) and then analysed on an ABI 3130XL sequencer.

\section{Sequencing analysis}

The sequences of nine NA gene were assembled, edited and aligned using the Sequencher programme (version 4.10) (Gene Codes Corporation, Ann Arbor, MI, USA). The construction of phylogenetic trees was performed using MEGA version 4.0 with the neighbourjoining method and bootstrap analysis of 1000 replicates.

\section{Results}

\section{Influenza virus surveillance}

From September 2014 to August 2015, 440 specimens were collected from 273 ILI and 167 SARI patients (Table 1). Two hundred and one (46\%) specimens tested positive for influenza virus: 135 (31\%) were type B, 38 (8\%) were A(H1N1)pdm09 and 25 (6\%) were A(H3N2). Subtyping of influenza B virus circulating in the 2014/15 season

\begin{tabular}{|c|c|c|c|}
\hline \multicolumn{4}{|c|}{$\begin{array}{l}\text { Table } 1 \text { Demographic characteristics and influenza prevalence among patients } \\
\text { with ILI and SARI, Morocco, 2014-2015 }\end{array}$} \\
\hline Characteristic & $\begin{array}{l}\text { ILI }(n=273) \\
\quad \text { No. }(\%)\end{array}$ & $\begin{array}{l}\text { SARI }(n=167) \\
\quad \text { No. }(\%)\end{array}$ & $\begin{array}{l}\text { Total }(n=440) \\
\quad \text { No. }(\%)\end{array}$ \\
\hline \multicolumn{4}{|l|}{ Age } \\
\hline 0-23 months & $5(1.8)$ & $71(42.5)$ & $76(17.3)$ \\
\hline $2-5$ years & $19(7.0)$ & $13(7.8)$ & $32(7.3)$ \\
\hline $6-15$ years & $50(18.3)$ & $14(8.4)$ & $64(14.6)$ \\
\hline $16-49$ years & $112(41.0)$ & $28(16.8)$ & $140(31.8)$ \\
\hline 50-64 years & $59(21.6)$ & $17(10.2)$ & $76(17.3)$ \\
\hline$\geq 65$ years & $16(5.9)$ & $15(9.0)$ & $31(7.1)$ \\
\hline Unknown & $12(4.4)$ & $9(5.4)$ & $21(4.8)$ \\
\hline \multicolumn{4}{|l|}{ Sex } \\
\hline Female & $155(56.7)$ & $81(48.5)$ & $236(53.6)$ \\
\hline \multicolumn{4}{|l|}{ Influenza subtype } \\
\hline A (H1N1)pdm09 & $24(8.8)$ & $14(8.4)$ & $38(8.6)$ \\
\hline $\mathrm{A}(\mathrm{H} 3 \mathrm{~N} 2)$ & $22(8.1)$ & $3(1.8)$ & $25(5.7)$ \\
\hline A unsubtypeable & NA & $3(1.8)$ & $3(0.7)$ \\
\hline B & $113(41.4)$ & $22(13.2)$ & $135(30.7)$ \\
\hline Negative & $114(41.8)$ & $125(74.9)$ & $239(54.3)$ \\
\hline
\end{tabular}

ILI=influenza-like illness; SARI = severe acute respiratory illness. 


\begin{tabular}{|c|c|c|c|c|c|}
\hline \multirow[t]{2}{*}{ NAls } & \multirow{2}{*}{$\begin{array}{l}\text { Origin of } \\
\text { specimen }\end{array}$} & \multicolumn{4}{|c|}{ IC50 (nM) } \\
\hline & & No. analysed & Median (range) & Mean \pm SD & $\begin{array}{l}\text { NAI susceptibility } \\
\text { (fold change) }\end{array}$ \\
\hline \multirow[t]{3}{*}{ Oseltamivir } & ILI & 28 & $\begin{array}{c}33.94 \\
(11.60-46.44)\end{array}$ & $31.98 \pm 9, .57$ & $S(1)$ \\
\hline & SARI & 30 & $\begin{array}{c}31.84 \\
(12.04-59.01)\end{array}$ & $31.52 \pm 11.17$ & $S(1)$ \\
\hline & & 2 & $\begin{array}{c}225.40 \\
(200.60-250.20)\end{array}$ & $225.44 \pm 35.07$ & RS (6-8) \\
\hline \multirow[t]{2}{*}{ Zanamir } & ILI & 28 & $\begin{array}{c}3.45 \\
(0.67-7.51)\end{array}$ & $3.37 \pm 1.79$ & $S(1)$ \\
\hline & SARI & 32 & $\begin{array}{c}3.60 \\
(0.56-8.61)\end{array}$ & $3.74 \pm 2.11$ & $S(1)$ \\
\hline
\end{tabular}

Median IC50 values for the drug among susceptible viruses (outliers excluded in calculation). IC50 values calculated using JASPER curve-fitting software.

Mean and SD of IC50 values for the drug among susceptible viruses (outliers excluded in calculation).

Fold changes in IC50 determined by comparing IC50 of test viruses to the mean IC50 (outliers excluded) by respective drug and influenza type/subtype.

$I L I=$ influenza-like illness; $N A I=$ neuraminidase inhibitor; $R S=$ reduced susceptibility; $S=$ sensitive; SARI = severe acute respiratory illness; $S D=$ standard deviation.

showed that all belonged to B/Yamagata/16/88 lineage.

\section{Phenotypic analysis}

Sixty of 135 influenza B viruses had a titre of $\geq 1$ in 4 in the haemagglutination test and were subject to the NA inhibition assay. The assay showed that all influenza $B$ viruses were sensitive to NAIs, except B/Morocco/176H/2015 and $\mathrm{B} /$ Morocco/CP10/2015, with IC50 values of 200.60 and $250.20 \mathrm{nM}$, respectively (Table 2). Therefore, these 2 viruses were considered as outliers and demonstrated a 6-8-fold reduced susceptibility to oseltamivir compared to the mean IC50 (31.52 nM) of the same virus types. The mean IC50 for all influenza $B$ viruses tested, not including the outliers, for zanamivir (3.62 nM) was low compared with the mean IC50 for oseltamivir $(31.74 \mathrm{nM})$, reflecting increased sensitivity $(\times 9)$ of influenza $B$ virus to zanamivir compared with oseltamivir.

\section{Phylogenetic and molecular analysis}

TheNA of 9 of 60 influenza B virusstrains tested in the fluorescent NA inhibition assay was sequenced: B/Morocco/ CP10/2015, B/Meknes/35/2014, B/ Sale//70/2014, B/Agadir/68/2014,
B/Morocco/176H/2015, B/Oujda/96/2014, B/Morocco/102/2015, B/Morocco/43H/2014 and B/ Meknes/32/2014. The respective GISAID accession numbers were: EPI_ISL_216533, EPI_ISL_175139, EPI ISL 17514, EPI ISL 175086, EPI_ISL_215754, EPI_ISL_171966, EPI_ISL_215717, EPI_ISL_215716 and EPI_ISL_171964). The phylogenetic and molecular analysis of the 9 NA sequences (Figure 1) showed that they were related genetically to B/ Phuket/3073/2013; the vaccine prototype strain for the 2015-2016 season (18). The NA of the 2 isolates with reduced sensebitity to oseltamivirharboured the specific mutations of $\mathrm{B} /$ Phuket/3073/2013 (Figure 2). The B/ Morocco/CP10/2015 strain collected from a deceased patient confirmed as influenza positive harboured the specific K371N amino-acid substitution mutation, which is not known to confer drug resistance on influenza $B$ viruses.

\section{Discussion}

We analysed the antiviral susceptibility of the predominant influenza B virus circulating in Morocco during the 2014/15 season using the phenotypic
NA inhibition assay (NA Fluor Influenza Neuraminidase Assay kit) as well as sequencing of the NA gene. We found that all the influenza B viruses exhibited normal sensitivity for zanamivir. This is in accordance with studies of influenza drug susceptibility worldwide, in which only a few strains with reduced sensitivity to zanamivir have been reported $(19,20)$. This could be explained by the characteristic structure and conformation of this drug. The higher structural homology with the NA natural substrate, sialic acid, and lower use of zanamivir (compared with oseltamivir) are the most probable factors to account for the infrequent isolation of zanamivirresistant variants worldwide (8).

Sixty influenza B viruses isolated in MDCK cells and tested by fluorescent NA inhibition test were sensitive to oseltamivir (<5-fold change in IC50), except for 2 isolates that demonstrated a 6-8-fold reduced susceptibility compared with the mean IC50 (outliers excluded) according to drug and influenza virus type/subtype. Both isolates were collected from SARI patients without historical drug exposure. A few previous studies have revealed influenza B virus with reduced susceptibility to NAIs, particularly oseltamivir $(2,21,22)$. 


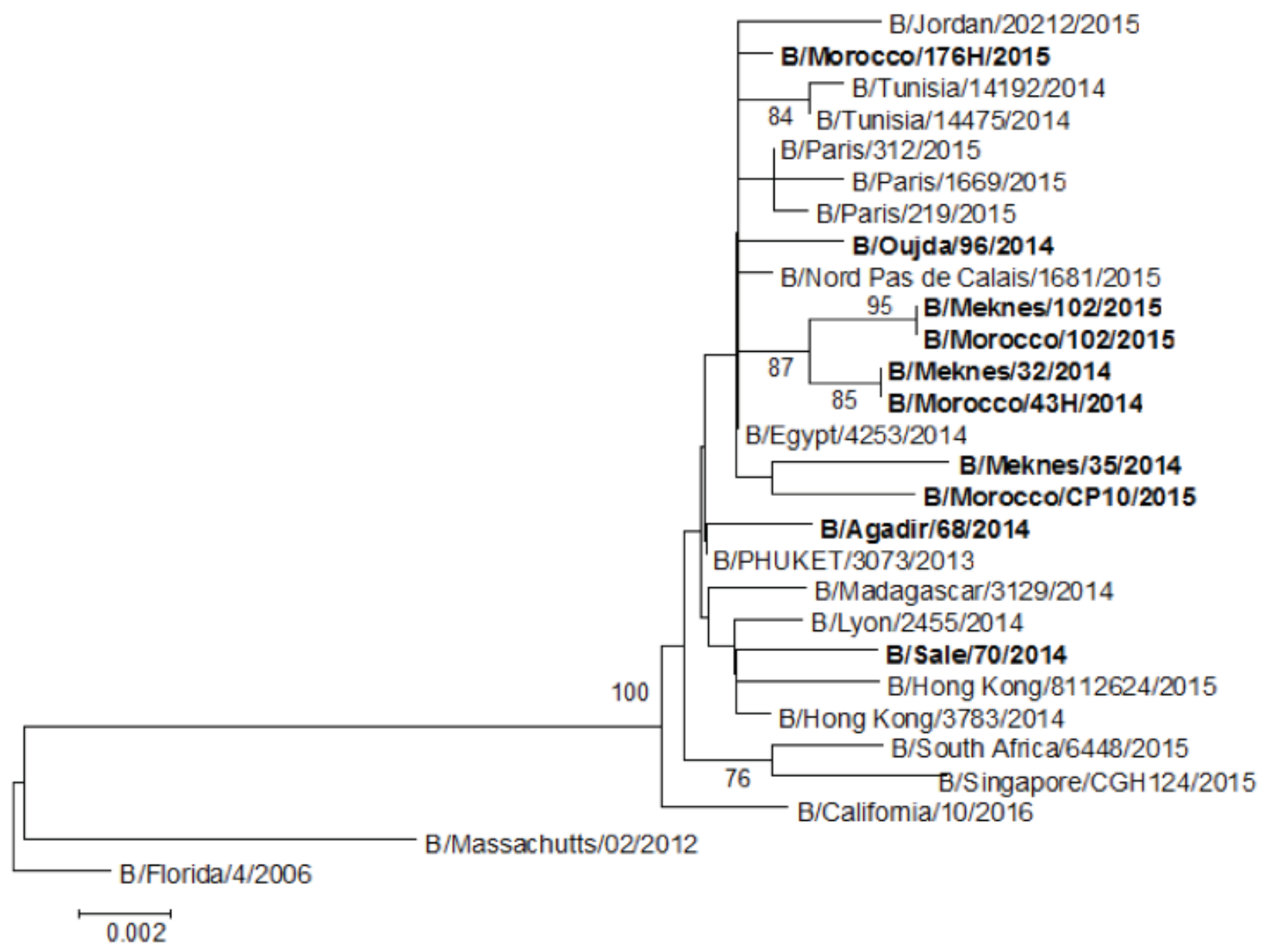

Figure 1 Phylogenetic comparison based on nucleotide sequences of B/Yamagata lineage of NA gene with that of vaccine viruses and strains from other countries (the tree was rooted with $\mathrm{B} / \mathrm{Florida} / 02 / 2012 \mathrm{Na}$ gene and was created using the neighbour-joining and bootstrap analysis of 1000 replicates method).

As indicated by substantially higher oseltamivir IC50 values, influenza B viruses appear to be more sensitive to zanamivir than oseltamivir. Most systematic antiviral surveillance evaluating NAI susceptibility of influenza B viruses has showed that oseltamivir is less effective at treating influenza $B$ than influenza A infections in children $(23,24,25)$. Sequencing analysis of the NA gene of 9 influenza $B$ viruses compared with the reference B/Massachusetts/02/2012 strain showed that they were related genetically to the B/Phuket/3073/2013 vaccine virus for the 2015-2016 influenza season.

B/Morocco/CP10/2015 and B/ Morocco/176H/2015 showing reduced sensitivity to oseltamivir did not harbour any substitution mutations known to confer reduced sensitivity to influenza B strains, such as G109E, G402S, D198N and I221T detected in isolates from patients treated with NAIs (2, 8). However, B/Morocco/ CP10/2015 harboured amino acid substitution K371N (B numbering) located among the highly conserved catalytic NA residues. This residue seems highly conserved from other alignment, so this looks like an unusual change and may mean that it is responsible for the change. Residue substitution R374I (B numbering) is only 3 amino acids long and does have a proven effect on NAI susceptibility. To prove the probable role of the K371N mutation in NAI resistance, reverse genetics analysis is needed.
In Morocco, prior to the pandemic of 2009, influenza drugs, especially NAIs, were rarely used for influenza prophylaxis or treatment. This may be a reason for drug-sensitive strains. It also shows that there has been no circulation of "fit" resistant viruses in Morocco that are highly transmissible such as the $\mathrm{H} 275 \mathrm{Y} \mathrm{A}(\mathrm{H} 1 \mathrm{~N} 1)$ seasonal variant in 2007/08.

\section{Conclusion}

We identified influenza B viruses with reduced susceptibility to oseltamivir, thus highlighting the importance of influenza antiviral susceptibility surveillance in Morocco, even though the use of NAIs is low. 


\section{Acknowledgements}

We would like to thank all the physicians and nurses in the public and private sector who contributed to the collection of samples at the sentinel sites.

Funding: This work was supported through funding by the Centers for Disease Control and Prevention
(CDC) grant no. 5U51CI000469 and the WHO Pandemic Influenza Preparedness Framework.

Competing interests: None declared..
B/MASSACHUSETTS/02/2012 B/ PHUKET/3073/2013 B/Meknes/35/2014 B/Morocco/CP10/2015 B/Sale/70/2014 B/Meknes/102/2015 B/Oujda/96/2014 B/Meknes/32/2014 B/MORROOD/4 3H/2014 $\mathrm{B} / \mathrm{Agadir} / 68 / 2014$ B/Morocoo/176H/2015

B/MASSACHUSETTS/02/2012 B/ PHUKET/3073/2013 B/Meknes/35/2014 B/Morocco/CP10/2015 B/Sale/70/2014 B/Meknes/102/2015 B/Oujda/96/2014 B/Meknes/32/2014 B/MORROOO/4 3H/2014 B/Agadir/68/2014 B/Morocco/176H/2015

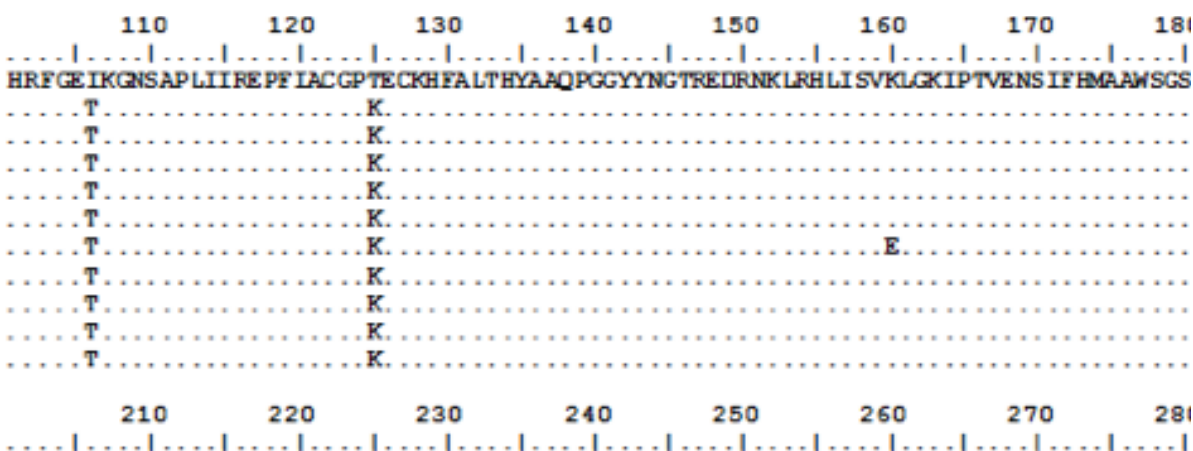

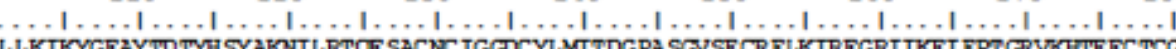
作

$\begin{array}{llllllll}310 & 320 & 330 & 340 & 350 & 360 & 370 & 380\end{array}$ B/MASSACHUSETTS/ $02 / 2012$ PEVKLNVETDTAEIRLMCTETYLDTPRPNDGSITGPCESDGDKGSGGIKGGEVHRMASKIGRYY B/PHUKET/ $3073 / 2013$ B/Meknes/35/2014 B/Morocco/CP10/2015

B/Sale/70/2014 B/Meknes/102/2015 B/Oujda/96/2014 B/Meknes/32/2014 $\mathrm{B} / \mathrm{MORROCO} / 43 \mathrm{H} / 2014$ $\mathrm{B} /$ Agadir/ $68 / 2014$ B/Morocco/176H/2015

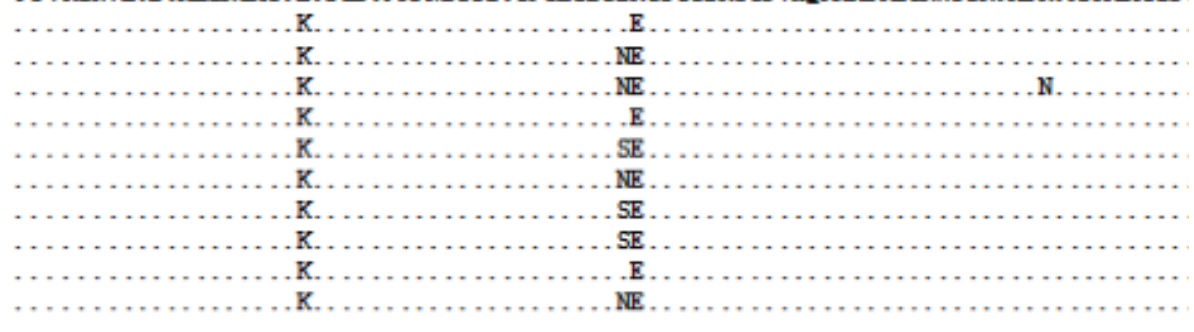

$\begin{array}{llllll}410 & 420 & 430 & 440 & 450 & 460\end{array}$ $\ldots 1 \ldots 1 \ldots 1 \ldots 1 \ldots 1 \ldots 1 \ldots 1 \ldots 1 \ldots 1 \ldots 1 \ldots 1 \ldots 1 \ldots 1 \ldots$ B/MASSACHUSETTS/02/2012 VSMEEPGWYSPGEIKDKKCDVPCIGIDMVHDGGTTWHSAATAIYCLMGSGDLLWDTVTGVMA * B/PHUKET $/ 3073 / 2013$

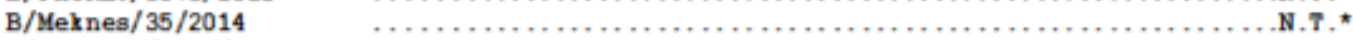

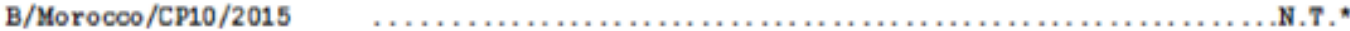

$\mathrm{B} / \mathrm{Sale} / 70 / 2014$ B/Meknes/102/2015 B/Oujda/96/2014 B/Meknes/32/2014 B/MORROOO/43H/2014

B/Agadir/68/2014 B/Morocco/176H/2015

Figure 2 Comparison of amino acid sequences of NA gene of Yamagata lineage Moroccan influenza B virus strains with reference strain B/Massachusetts/02/2012, showing the specific substitutions. 
1. Schirmer P, Holodniy M. Oseltamivir for treatment and prophylaxis of influenza infection. Expert Opin Drug Saf. 2009;8(3):357-71.

2. Wang D, Sleeman K, Huang W, Nguyen HT, Levine M, Cheng $\mathrm{Y}$, et al. Neuraminidase inhibitor susceptibility testing of influenza type B viruses in China during 2010 and 2011 identifies viruses with reduced susceptibility to oseltamivir and zanamivir. Antiviral Res. 2013;97(3):240-4.

3. Barr et al.2010. Epidemiological, antigenic and genetic characteristics of seasonal influenza A (H1N1), A (H3N2) and B influenza viruses: basis for the $\mathrm{WHO}$ recommendation on the composition of influenza vaccines for use in the 2009-2010 northern hemisphere season. Vaccine. 2010 Feb 3;28(5):115667.

4. Burnham AJ, Baranovich T, Govorkova EA. Neuraminidase inhibitors for influenza B virus infection: efficacy and resistance. Antiviral Res. 2013;100(2):520-34.

5. Sheu TG, Deyde VM, Okomo-Adhiambo M, Garten RJ, Xu X, Bright RA, Butler EN, Wallis TR, Klimov AI, Gubareva LV. Surveillance for neuraminidase inhibitor resistance among human influenza A and B viruses circulating worldwide from 2004 to 2008. Antimicrob. AgentsChemother. 2008; 52:3284-3292.

6. Okomo-Adhiambo M, Sleeman K, Lysen C, Nguyen HT, Xu X, Li Y, Klimov Al, Gubareva LV.Neuraminidase inhibitor susceptibility surveillance of influenza viruses circulating worldwide during the 2011 Southern Hemisphere season. Influenza and other respiratory viruses. 2013

7. Hatakeyama S, Ozawa M, Kawaoka Y. In vitro selection of influenza B viruses with reduced sensitivity to neuraminidase inhibitors Clin Microbiol Infect. 2011 Sep; 17(9): 1332-1335.

8. Nguyen HT, Fry AM, Gubareva LV. Neuraminidase inhibitor resistance in influenza viruses and laboratory testing methods. Antivir Ther. 2012:17:159-73

9. Barakat A, Ihazmad H, Benkaroum S, Cherkaoui I, Benmamoun $A$, Youbi $M$, et al. Influenza surveillance among outpatients and inpatients in Morocco, 1996-2009. PLoS One. 2011;6(9):e24579.

10. Barakat A, Ihazmad H, El Falaki F, Tempia S, Cherkaoui I, El Aouad R. Pandemic influenza A(H1N1)2009 in Morocco, 2009-2010: epidemiology, transmissibility and factors associated with fatal cases. J Infect Dis. 2012;206 Suppl. 1:S94-100.

11. WHO information for molecular diagnostic of influenza virus humans-update. Geneva: World Health Organization;2011(http://www.who.int/influenza/resources/documents/molecular_diagnosis_influenza_virus_humans_update_201108, accessed 27 April 2016).

12. Manualforthelaboratory diagnostic and virological surveillance of influenza. Geneva: World Health organization;2011(http:// www.who.int/influenza/gisrs_laboratory/manual_diagnosis_surveillance_influenza/en/, accessed 24 May2016).
13. International Society for Influenza and Other Respiratory Virus Diseases. (https://isirv.org/site/index.php/special-interestgroups/antiviral-group-home, accessed 27 April2016).

14. Okomo-Adhiambo M, Michin VP, Sleeman K, Sagur E, Guevera $\mathrm{H}$, Reisdorf E. Standardizing the influenza neuraminidase inhibition assay among United States public health laboratories conducting virological surveillance. Antiviral Res. 2016;128:28-35.

15. Okomo-Adhiambo M, Sleeman K, Ballenger K, Nguyen HT, Mishin VP, Sheu TG, et al. Neuraminidase inhibitor susceptibility testing in human influenza viruses: a laboratory surveillance perspective. Viruses. 2010;2(10):2269-89.

16. Okomo-Adhiambo M, Nguyen HT, Anwar AE, Sleeman K, Fry AM, Gubareva LV. Drug susceptibility surveillance of influenza viruses circulating in the United States in 2011-2012: application of the WHO antiviral working group criteria. Influenza Other Respi Viruses. 2014;8(2):258-65.

17. Meetings of the $\mathrm{WHO}$ working group on surveillance of influenza antiviral susceptibility geneva, November 2011 and June 2012. Wkly Epidemiol Rec. 2012;87(39):369-80.

18. Recommended composition of influenza virus vaccines for use in the 2014-2015 northern hemisphere influenza season. Geneva: World Health Organization; 2012 (http://www.who. int/influenza/vaccines/virus/recommendations/en/, accessed 27 April 2016).

19. Monitoring of neuraminidase inhibitor resistance among clinical influenza virus isolates in Japan during the 2003-2006 influenza seasons. Wkly Epidemiol Rec. 2007;82(17):149-50.

20. Sheu TG, Deyde VM, Garten RJ, Klimov AI, Gubareva LV. Detection of antiviral resistance and genetic lineage markers in influenza B virus neuraminidase using pyrosequencing. Antiviral Res. 2010;85:354-60.

21. Bastien N, Gubbay JB, Richardson D, Sleeman K, Gubareva L, Li Y. Detection of an influenza B virus strain with reduced susceptibility to neuraminidase inhibitor drugs. Clin Microbiol. 2011;49:4020-1.

22. Hatakeyama S, Sugaya $N$, Ito $M$, Yamazaki M, Ichikawa $M$, Kimura K, et al. Emergence of influenza B viruses with reduced sensitivity to neuraminidase inhibitors. JAMA. 2007;297:143542.

23. Ison MG, Gubareva LV, Atmar RL, Treanor J, Hayden FG. Recovery of drug-resistant influenza virus from immunocompromised patients: a case series. Infect Dis J. 2006;193:760-4.

24. Sugaya N, Mitamura K, Yamazaki M, Tamura D, Ichikawa M, Kimura K, et al. Lower clinical effectiveness of oseltamivir against influenza $B$ contrasted with influenza $A$ infection in children. Clin Infect Dis. 2007;44(2):197-202.</jrn>

25. Kawai N, Ikematsu H, Iwaki N, Maeda T, Kanazawa H, Kawashima T, et al. A comparison of the effectiveness of zanamivir and oseltamivir for the treatment of influenza A and B. J Infect. 2008;56:51-7. 